\title{
Effects of Structural Priming on Complex Sentence Production in Korean-English Bilingual Children
}

\author{
Bo Kyung Kim, Dongsun Yim \\ Department of Communication Disorders, Ewha Womans University, Seoul, Korea
}

Correspondence: Dongsun Yim, PhD

Department of Communication Disorders,

Ewha Womans University, 52 Ewhayeodae-gil,

Seodamun-gu, Seoul 03760, Korea

Tel: $+82-2-3277-6720$

Fax: +82-2-3277-2122

E-mail: sunyim@ewha.ac.kr

Received: September 2, 2016

Revised: November 10, 2016

Accepted: November 16, 2016

This work was supported by the Ewha Womans University Research Grant of 2016.

\begin{abstract}
Objectives: Complex sentences are important indicators in children's syntactic development. However, measurement of complex sentence development of bilingual children is challenging because of their individual variability. In this study, a structural priming paradigm was used to probe the underlying knowledge of complex sentence production in bilinguals. Methods: Participants were 30 Korean-English bilinguals between the ages of 6 to 12 years and 30 of their typically developing Korean monolingual peers. Children were asked to connect two types of sentences (compound and embedded) under a spontaneous and a priming condition. The total number of accuracies was measured and converted into percent accuracy. Results: Monolinguals outperformed bilinguals, and older children scored significantly higher than younger children on producing complex sentences. Participants performed significantly better in compound sentences and also showed better performance under priming condition. In both groups, the vocabulary knowledge significantly predicted production under the spontaneous condition. However, for priming condition, age and non-word repetition scores predicted performance in monolinguals whereas in bilinguals, non-word repetition scores and vocabulary knowledge predicted production under priming condition. Conclusion: Complex sentence production is associated with vocabulary size and working memory capacity. Monolinguals and bilinguals differ in sentence production ability, with bilinguals relying more on vocabulary knowledge than monolinguals.
\end{abstract}

Keywords: Bilingual children, Complex sentence, Sentence structure priming
Complex sentence structures are the most distinct feature that represents language development in children as they advance through late elementary school to adolescence (Levey \& Polirstok, 2010). As children age, cognitive abilities including working memory capacity develop accordingly, enabling storage of more complex linguistic information and production of complex sentences (Montgomery \& Evans, 2009; Thomason et al., 2009). However, complex sentence development of children using two languages can differ since it is affected by two different language systems (Hatzidaki, Branigan, \& Pickering, 2011). Each language may not develop at the same rate according to the amount of exposure to each language and purpose of language use (Baker, 2006; Hoff et al., 2012; Şimşek, 2006; Yip \& Matthews, 2007). This may diminish the accurate ex- amination of complex sentence production in bilingual children.

Vocabulary development in bilingual individuals is subtly delayed early in life when measured and compared to each language norm (Bialystok, Luk, Peets, \& Yang, 2010; Fernandez, Pearson, Umbel, Oiler, \& Molinet-Molina, 1992; Hemsley, Holm, \& Dodd, 2006; Kohnert, 2007; Leseman, 2000; Luo, Luk, \& Bialystok, 2010; Teoh, Brebner, \& McCormack, 2012). Typically developing bilinguals demonstrate greater variability in language acquisition, since the two different languages interact within an individual child with increasing cognitive ability (Kohnert, Windsor, \& Ebert, 2009; Peña, Bedore, \& Zlatic-Giunta, 2002). Thus, it is difficult to accurately identify whether bilingual children truly have language learning difficulties or not (Bedore, Peña, García, \& Cortez, 2005; Kohnert 
et al., 2009; Pearson, 1998; Teoh et al., 2012; Yim, Jo, Han, \& Seong, 2016; Yim \& Windsor, 2010). Recent research has focused on cognitive-linguistic features in assessment using processing based tasks, such as working memory, statistical learning, and executive functions, in the bilingual population (Danahy, Windsor, \& Kohnert, 2007; Kohnert et al., 2009; Yim \& Rudoy, 2013). These methods are designed to tap cognitive-linguistic underpinnings rather than linguistic knowledge in bilingual children, emphasizing the importance of a basic cognitive mechanism for language learning. Since these processing-based tasks are designed to level the playing field, nonlinguistic stimuli and/or simple linguistic stimuli are generally used (Campbell, Dollaghan, Needleman, \& Janosky, 1997; Yim, Kim, \& Yang, 2016). Most of studies have documented the correlational and regression between these processing-based tasks and vocabulary knowledge in bilingual children (Kohnert, Windsor, \& Yim, 2006; Windsor, Kohnert, Lobitz, \& Pham, 2010). However, few studies have investigated how to directly measure bilinguals' higher language skills, such as complex sentence production (Bialystok, 2001; Lee, 2010; Thomas, Williams, Jones, Davies, \& Binks, 2014; Yim, Yoon, \& Lee, 2016; Yip \& Matthews, 2007).

In this study, the psycholinguistic paradigm of syntactic priming was used to test whether this method can be used to accurately examine complex sentence production in bilingual children. This method has been widely used in monolingual language comprehension and production (Branigan, Pickering, \& McLean, 2005; Luka \& Barsalou, 2005), and to test shared syntactic representation in bilingual children (Weber \& Indefrey, 2009). Thus, it is necessary to accurately examine complex sentence acquisition in bilingual children by comparing the complex sentence structures of bilingual children to that of their monolingual peers. For this reason, this study assessed complex sentence development of bilingual children using the structural priming task method.

The findings of Yip and Matthews (2007) in a study of bilingual Cantonese-English children suggested that the bilingual children produced relative clauses with different developmental patterns; these Cantonese-English bilingual children produced object relatives prior to subject relatives, which never occurred in monolingual English-speaking children. The interaction of the two languages was the main reason. In explaining bilingual language development, many studies have demonstrated that the two languag- es interact with each other during childhood. The importance of language environment was emphasized in a study (Şimşek, 2006) that clarified that the different amount of exposure to a certain language determines the amount of complex sentence production. The participants were Turkish monolinguals, Turkish-German bilinguals, and Turkish, German, and English multilingual adults. The amount of complex sentence production and its variability in their speech was compared. The frequency of complex sentences decreased as the number of spoken languages increased, possibly because bilinguals did not have sufficient opportunity to be exposed to each language. Interestingly, Turkish-German bilinguals produced more complex sentences in German, even though their first language was Turkish. No matter what their first language was, it was the current language environment, the dominant language directly related to the amount of exposure that was responsible for language development.

In an effort to find the process of language learning, researchers manipulated the language environment to teach second language learners more effectively. Some studies have demonstrated the benefit of structural priming in second language development. McDonough and MacKey (2008) investigated whether structural priming could be associated with second language development. Forty-six English as a Second Language (ESL) learners carried out a 20-minute communicative activity session with an advanced English speaker. Participants were asked to use challenging sentence structures during the interaction. The participants were able to use advanced forms of questions after the session. The results supported the idea that the experience and the exposure lead to syntactic development, and structural priming intensifies language learners' stored linguistic knowledge (McDonough \& MacKey, 2008). Similarly, bilingual children without any explicit instructions or reinforcements were able to produce correct complex sentence structures when there were modeling sentences in their environment (Harris \& Hassemer, 1972). In summary, structural priming facilitates syntactic development because it is dependent on previous experiences or exposure to a certain syntactic form, which is also the case for implicit learning. Implicit learning is beneficial in second language production, facilitating the acquisition of abstract linguistic representation (Ellis, 2005).

It is believed that the languages bilinguals produce are intertwined 
together at an abstract level. Shin and Christianson (2009) examined Korean-English bilinguals to show whether they have shared sentence processing. Syntactically parallel Korean and English dative sentences were used to ascertain the existence of cross-linguistic structural priming. Structural priming could occur across languages, and there was shared sentence processing at the functional level. This indicates that shared sentence processing influences sentence production in bilingual individuals. Therefore, by tapping the linguistic processing at the abstract level, structural priming is not restricted to ephemeral language performance; it should be considered as a means of investigating deeper linguistic representation related to language knowledge (Bock, Dell, Chang, \& Onishi, 2007). Thus, in this study we used structural priming to assess bilingual children's complex sentence production from a higher abstract level.

\section{Factors influencing structural priming}

Structural priming assumes that speakers produce structural patterns that are influenced by the sentences just heard (Bock, 1986). This occurs even when the speakers' sentences do not have the same words or nominal relations used in the preceding sentence (Leonard, 2011). Structural priming has been used to examine language processing in adults and children (Goldwater, Tomlinson, Echols, \& Love, 2011; Savage, Lieven, Theakston, \& Tomasello, 2006). In many structural priming tasks, participants are asked to repeat sentences spoken by an experimenter, and then are told to describe a picture or finish the sentence. Participants are more likely to describe the picture using the structure of the sentence they just heard. Structural priming has proven to be a useful assessment tool for sentence production. In addition, the structural priming task has been used to investigate what type of linguistic information is primed. Abstract linguistic level appears to be affected by priming (Bock \& Loebell, 1990; Fox Tree \& Meijer, 1999; Shin \& Christianson, 2009; Tsiamtsiouris \& Cairns, 2009). Since structural priming is an implicit method to assess abstract syntactic representations, it will facilitate tapping language knowledge. When a sentence is primed, it means that the priming sentence has affected the latter's abstract structural representation (Scheepers et al., 2011). Furthermore, the function of structural priming in grammatical development is emphasized, since priming sentences could stimulate children to produce new sentence structures (Leonard, 2011).

One of the factors that influences structural priming is participant age. Unlike the adult participants who establish mature linguistic representations, the development of linguistic representations has been investigated in children (Savage et al., 2006; Thothathiri \& Snedeker, 2008). Goldwater et al. (2011) argued that children use structural priming as a type of analogy and the shared surface structural similarity between a prime sentence and the target sentence increases children's production of more complex syntactic structures. In another study, a total of 115 children aged from 4 to 5 years were asked to repeat an experimenter's sentence and describe a picture on their own. The younger group was able to show the semantic priming effect only when there was surface similarity, while the older group showed both semantic and syntactic priming effects. This means that children without both semantic and syntactic knowledge do not show the structural priming effect; the necessary developing language knowledge is not limited to syntactic development, but also depends on semantic knowledge. Structural priming stimulates children's grammatical development in children with sufficient semantic language experience. Children can produce longer and more complex sentences with the presence of previously-heard sentences (Harris \& Hassemer, 1972). Even though children showed priming effect, there were no differences in the performance of third and fourth grade students. This indicates that when children reach a certain age, their sentence development reaches a plateau.

Another factor that is related to structural priming is cognitive abilities. Malhotra (2009) formulated a mathematical model to test various aspects of structural priming, and reported the relationship of structural priming to cognitive processes of attention, working memory, and long-term memory. Ledoux, Traxler, and Swaab (2007) reported that some kind of lexical information about verbs remained active in working memory, relating this to the syntactic properties of verbs and their use in different syntactic routines. The study used a sentence recall experiment using event-related potentials (ERP). Priming effects were related to repetition effects of verbs across prime and target sentences. The syntactic form repetition led to changes in the representation of syntactic information stored in the verb. These findings suggest that verbs are im- 
portant in structural priming and there must be subsequent working memory capacity to store the linguistic information structural priming carries.

According to Reitter, Keller, and Moore (2011), priming results from the activation that spreads from working memory to longerterm memory, with lexical information being crucial in structural priming. Other studies have addressed the relationship between structural priming and language knowledge represented as longterm language experience. Bernolet and Hartsuiker (2010) examined whether structural priming is correlated with prediction of verbs in sentences. Fifty-seven adults were tested with double object dative priming and prepositional object dative priming in a picture description task. Sentence structures featuring less common or less predicted verbs had a greater priming effect than sentence structures with relatively preferred or predicted verbs. Interestingly, though these results demonstrated the implicit learning effect of structural priming, at the same time they showed that implicit learning effects occurred more when unfamiliar verbs were given. Past experience with certain verbs determined the syntactic structure. Structural priming strengthens mappings between the meanings and syntactic structure. Furthermore, since it serves as a facilitator, the person must have language knowledge that features deeper linguistic representation to relate the meanings and linguistic structure.

Ferreira, Bock, Wilson, and Cohen (2008) compared four adults with anterograde amnesia to four normal adults in a structural priming task. Both groups showed a structural priming effect in describing pictures, but the participants with amnesia showed poorer recall in remembering the prime sentence. Because of the anterograde amnesic effect, patients had trouble storing new information and were poor at remembering what happened. Even though there was no recollection of the prime sentence, the participants were able to use the syntactic structure of the prime sentence. This suggests that when short-term memory is absent, structural priming depends solely on the working memory, and long-term language experience may have affected the production of the syntactic structure. Thus, structural priming influences language knowledge and language experience. In summary, structural priming can tap abstract linguistic representations. In doing so, language knowledge and previous experience in the language is advanta- geous to deduce the link between meanings and sentence structures. Furthermore, cognitive processes, such as sufficient working memory capacity, will be needed for structural priming to occur.

The hypothesis of the current study is that even though bilingual children might show delays in complex sentence development due to lack of experience in the language being tested, their performance will be enhanced under the presence of a prime sentence if they have proper language experiences and knowledge along with underlying cognitive tools, such as working memory. In this study, we investigated whether poor performance in bilingual children is associated with language knowledge. If structural priming facilitates underlying language knowledge, then the performance of bilingual individuals should not differ from the performance monolinguals. This study also examined the interaction of structural priming with vocabulary size (Marchman, Fernald, \& Hurtado, 2010) and working memory. Lastly, the study explored whether different tendencies exist between monolinguals and bilinguals in explaining complex sentence production.

To examine the effects of structural priming in complex sentence production, this study divided the complex sentences into compound sentence and embedded sentence groups. A pretestpriming-posttest design was used to measure the performances. The performances of Korean-English bilingual children were compared with Korean monolingual children.

\section{METHODS}

\section{Participants}

Sixty children age 6 to 12 years comprised 30 Korean speaking monolingual children with typically developing language skills (MO group; mean age $=8.4$ years, $\mathrm{SD}=1.7$ ) and 30 Korean-English bilingual children with typically developing language skills (BI group; mean age $=8.9$ years, $\mathrm{SD}=1.9$ ). For bilingual children, Korean was their first language at home and English was the language spoken in school. All bilingual children attended English speaking schools but the dominant language for most of them was Korean. Along with the experimental task, all children passed a hearing screening test $(1,000-4,000 \mathrm{~Hz}, \mathrm{~dB}=20)$, showed normal nonverbal intelligence (Korean-Kaufman Assessment Battery for Children, K-ABC; Moon \& Byun, 2003), and language skills with- 
Table 1. Demographic characteristics for each group

\begin{tabular}{lccccc}
\hline & Age $(\mathrm{mo})$ & K-ABC & REVT-R & PPVT & NWR (\%) \\
\hline M0 group ( $=30)$ & $100.5(20.4)$ & $123.4(9.3)$ & $102.8(28.4)$ & - & $92.8(8.3)$ \\
Bl group ( $\mathrm{N}=30)$ & $107.5(23.1)$ & $125.8(8.0)$ & $106.6(29.6)$ & $86.3(7.1)$ & $95.0(4.2)$ \\
\hline
\end{tabular}

Values are presented ad mean (SD).

K-ABC=Korean Kaufman Assessment Battery for Children (Moon \& Byun, 2003); REVT-R=Receptive and Expressive Vocabulary Test-receptive only (Kim, Hong, Kim, Jang, \& Lee, 2009); PPVT = Peabody Picture Vocabulary Test fourth edition (Dunn \& Dunn, 2007); NWR=non-word repetition task (Lee, Kim, \& Yim, 2013); M0=typically developing Korean speaking monolingual children; $\mathrm{Bl}=$ typically developing Korean-English bilingual children.

in average range (Receptive and Expressive Vocabulary Test, REVT; Kim, Hong, Kim, Jang, \& Lee, 2009). Children with history of any type of parent-reported developmental delay were excluded. Bilingual children were tested using the Peabody Picture Vocabulary Test fourth edition (PPVT-4; Dunn \& Dunn, 2007) and also scored within normal range. Based on parental reports, language development was equivalent to their peers and the children had not received special education for language or repeated a grade. The children had a minimum of 3 to a maximum of 8 years of exposure to English. The non-word repetition task (NWR; Lee, Kim, \& Yim, 2013) was performed to investigate working memory capacity prior to the experimental task. The task contained 20 Korean nonwords that were 2-6 syllables long. Demographic characteristics for each group are provided in Table 1.

\section{Experimental tasks}

The sentence combining task (Lee, 2010) was modified and used to measure the complex sentence production of the children. This task originally used two to four simple sentences as a set to form one complex sentence. Some of the sentences in the sets were deleted so that each set could include two sentences. Each sentence consisted of two to three words, depending on the syntactic structure, which consisted of subject-object-verb, subject-complementverb, and subject-verb. The words used in the sentence represented high-frequency vocabulary for the kindergarteners and lower graders in elementary school (Lee, 2010). The sentences were divided into two groups (compound and embedded types), since children develop relative operators and the subsequent structures later than other syntactic structures (McKee \& McDaniel, 2001). Forty sets of simple sentences, each containing two simple sentences appeared in four different conditions. In the first condition, children heard two simple sentences and were told to connect the sentences to form a compound sentence without any sample answer (e.g., "I woke up in the morning" and "I brushed my teeth"). In the second condition, children were instructed to do the same, but the sentences they produced would be an embedded sentence (e.g., "I lost my doll" and "Mom bought me the doll"). After the children completed the sets in the first and the second conditions, they were told to do the same again for priming purposes. Prime sentences serving as sample answers were given for the children to repeat before the real task began. Thus, in the third and the fourth conditions, two prime trials were done before the target session.

All children went through both the spontaneous and priming sessions of the task. In the spontaneous session, the children were told to connect the two sentences they heard on their own without any sample answers. After they completed 20 sets of sentences, they moved on to the priming session, in which they heard and repeated the answer from the experimenter during the practice sets. After the priming practice, another set of 20 sentences were given to the children to combine.

The sentences were read by a native Korean speaker and recorded into MP3 files. The sentences were presented through the headset and the sentences the children produced were audio-recorded using the headset.

\section{Procedure}

All children participated in the complex sentence task either in their school or at home. They were tested individually in a quiet room by a trained experimenter. Participants wore a headphone and were asked to listen to the sentences. In the first two conditions, each child was instructed to listen carefully to two short sentences and then to combine the two sentences into one sentence. Each child had the opportunity to practice. After each response the experimenter reinforced any answer regardless of the response. When the first 20 sentences were completed, the children took a short break and proceeded to the third and the fourth conditions. The 
directions were the same, except that they would listen and repeat the sample answer during the practice (prime) set.

\section{Analyses}

The sentences were then transcribed and scored by the experimenter. One point was given for each sentence combined correctly, with zero assigned to the sentences that were not combined in a correct form or to combined sentences that did not convey the same meaning. Performance on sentence combining test was examined using a 4-way mixed ANOVA with age and group as two between subject factors, and sentence types and two conditions as two within-subjects factors. To answer the second research question, a correlation analysis was used to determine if the performance in the sentence combining task was associated with vocabulary sizes and working memory capacity. A stepwise regression was used to investigate the factor predicting the performance in the sentence combining task. Twenty percent of the data was checked for reliability. Reliability was $90.6 \%$.

\section{RESULTS}

\section{Group performance}

Performances of the monolingual and bilingual children are summarized in Table 2.

Four-way mixed ANOVA revealed significant main effects, with bilinguals performing worse than monolinguals $\left(F_{(1,56)}=5.855\right.$, $p=.02, \eta=.01$ ), and older children scoring significantly higher than younger children $\left(F_{(1,56)}=107.599, p<.001, \eta=.66\right)$. Significant main effects were evident for sentence types and conditions. Children performed significantly better in compound sentences $\left(F_{(1,56)}=183.379, p<.001, \eta=.77\right)$ and also showed better perfor- mance under the sentence priming condition $\left(F_{(1,56)}=248.491\right.$, $p<.001, \eta=.82)$. Age and sentence type interaction was significant $\left(F_{(1,56)}=33.265, p<.001, \eta=.37\right)$ indicating that the difference between the performance level of the two sentence types reduced as children aged. The sentence type and condition interaction was also significant $\left(F_{(1,56)}=52.744, p<.001, \eta=.49\right)$ indicating that there was a greater sentence priming effect in embedded sentences (Figure 1).

\section{Correlations among age, language scores, and working memory}

The monolingual and bilingual groups showed similar patterns of performance across the task. The conditions and results are presented in Figures 2 and 3, respectively. The partial Pearson correlation adjusting for the contributions of chronological age are shown

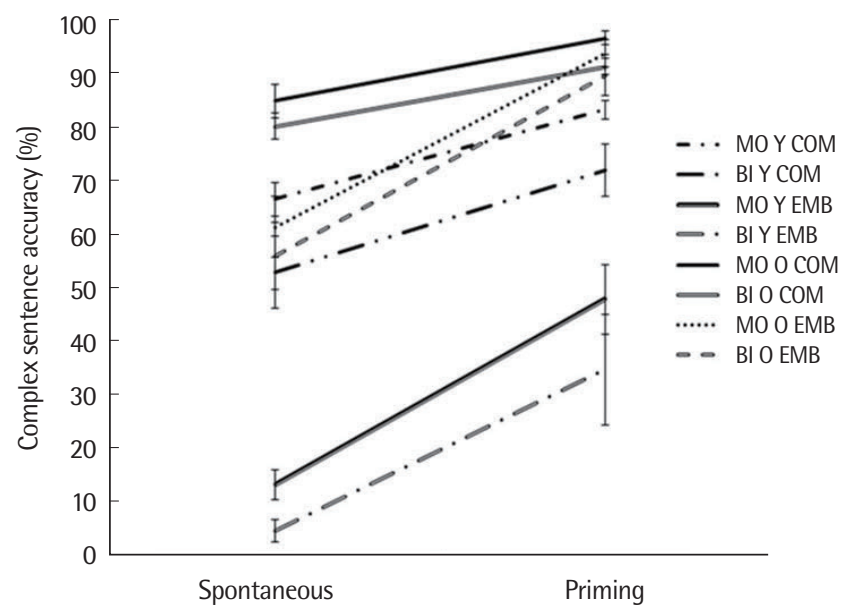

Figure 1. Group performance on complex sentence production by condition. $\mathrm{MO}=$ typically developing Korean speaking monolingual children; $\mathrm{BI}=$ typically developing Korean-English bilingual children; $Y=$ children under 8 years of age; $0=$ children over 8 years of age; $\mathrm{COM}=$ compound sentences; $\mathrm{EMB}=$ embedded sentences.

Table 2. Accuracy (\%) on sentence combining task under spontaneous and priming conditions by age group

\begin{tabular}{|c|c|c|c|c|c|}
\hline & \multirow{2}{*}{ Age } & \multicolumn{2}{|c|}{ Spontaneous } & \multicolumn{2}{|c|}{ Priming } \\
\hline & & Compound sentences & Embedded sentences & Compound sentences & Embedded sentences \\
\hline \multirow[t]{2}{*}{ MO group } & Young & $66.38(11.27)$ & $13.08(10.32)$ & 83.08 (6.30) & $47.69(23.51)$ \\
\hline & Old & $84.71(12.81)$ & 61.18 (23.69) & $96.47(4.93)$ & $93.53(10.57)$ \\
\hline \multirow[t]{2}{*}{ Bl group } & Young & $52.73(22.40)$ & $4.55(6.88)$ & 71.82 (16.01) & $34.55(34.17)$ \\
\hline & Old & 80.00 (11.06) & $55.79(27.56)$ & $91.05(6.58)$ & $89.47(16.82)$ \\
\hline
\end{tabular}

Values are presented as mean (SD). Compound sentences were tested first for all conditions.

$\mathrm{MO}=$ typically developing Korean speaking monolingual children; $\mathrm{Bl}=$ typically developing Korean-English bilingual children; Young=children under 8 years old; Old=children over 8 years old. 

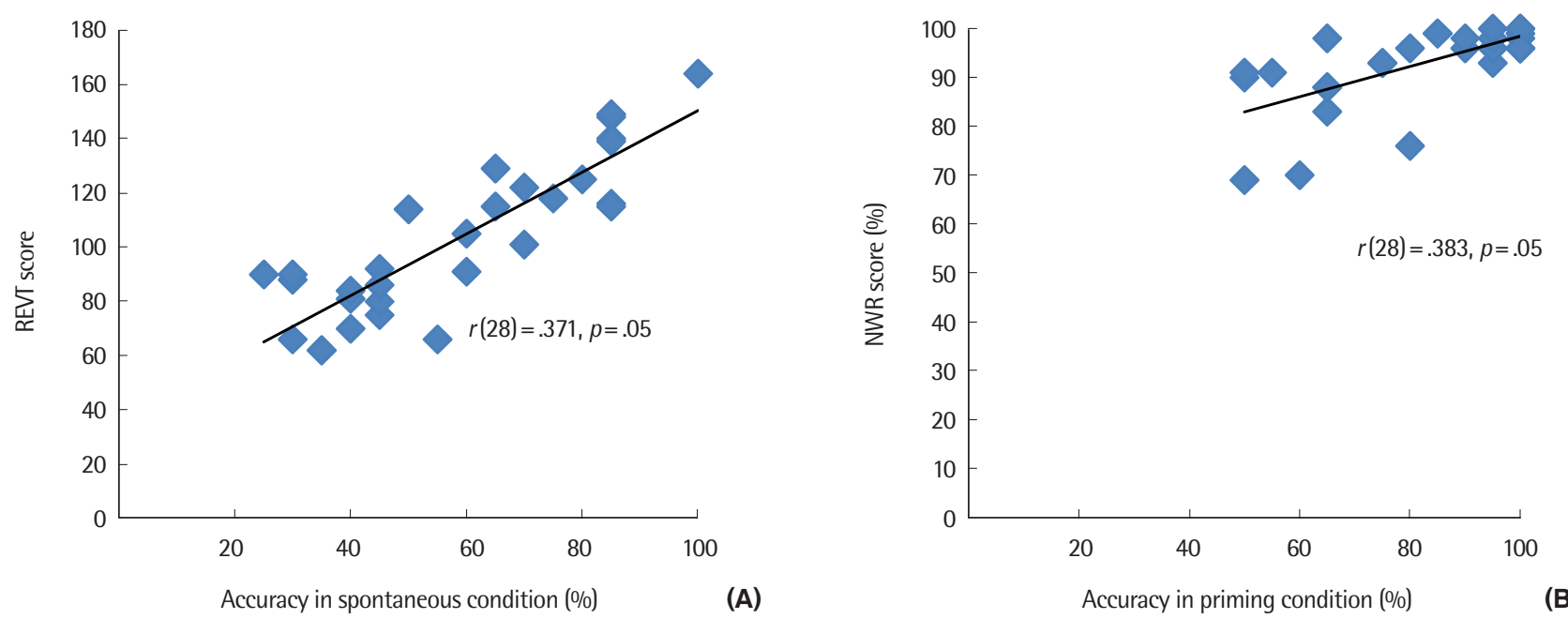

Figure 2. Scatterplot of task partial correlation covarying for age under the spontaneous condition (A) and priming condition (B) in monolinguals. The raw numbers are presented for REVT scores. REVT= Receptive and Expressive Vocabulary Test (Kim, Hong, Kim, Jang, \& Lee, 2009).
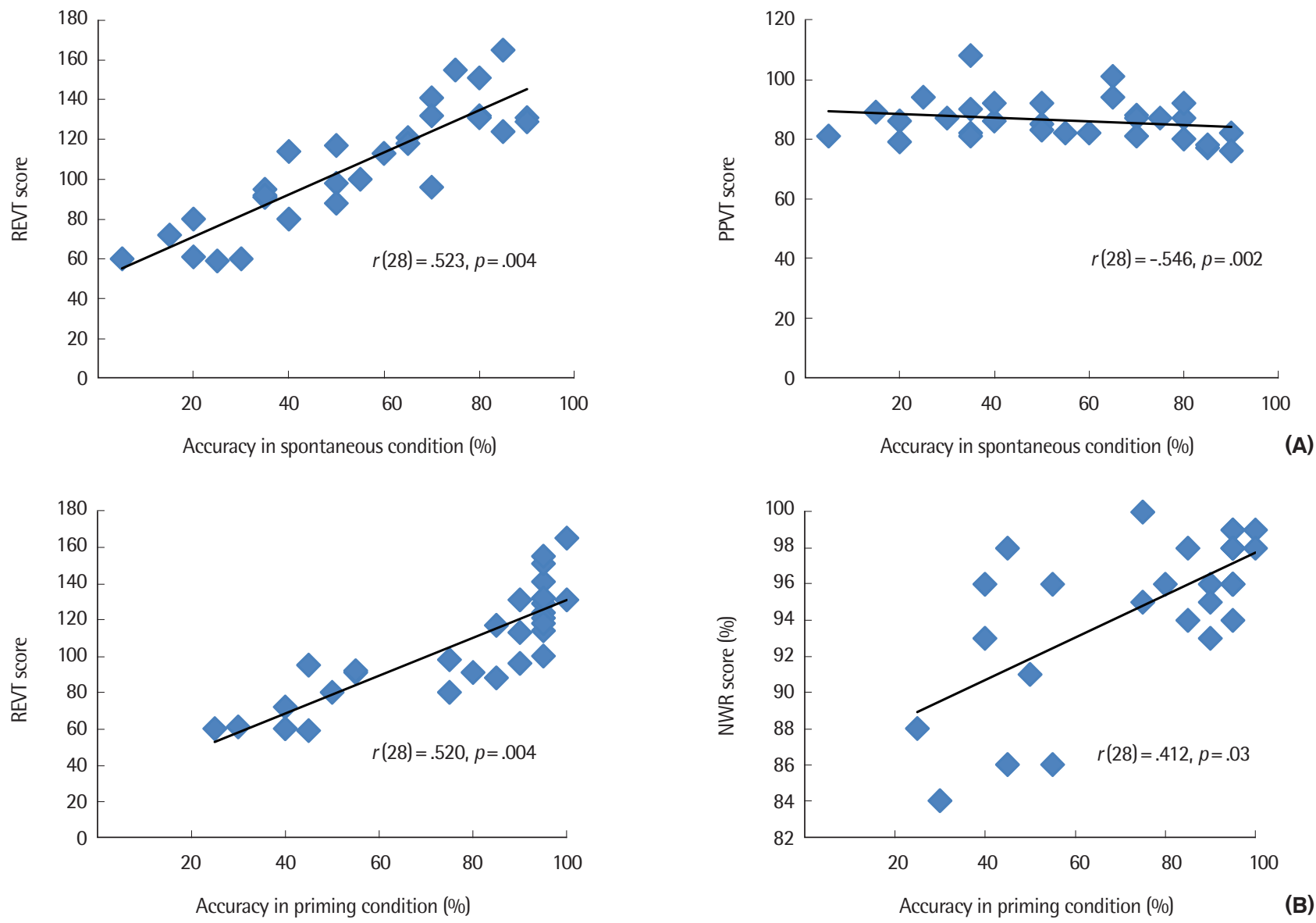

Figure 3. Scatterplots of task partial correlation covarying for age under the spontaneous condition (A) and priming condition (B) in bilinguals. The raw numbers are presented for REVT scores, and the standard scores are presented for PPVT scores. REVT=Receptive and Expressive Vocabulary Test (Kim, Hong, Kim, Jang, \& Lee, 2009); PPVT = Peabody Picture Vocabulary Test fourth edition (Dunn \& Dunn, 2007); NWR=non-word repetition task (NWR; Lee, Kim, \& Yim, 2013). 
in these figures.

For monolinguals, the total number of accuracies in the sentence combining task was significantly correlated only to REVT scores in the spontaneous condition $(r(28)=.371, p<.05)$. NWR scores were significantly correlated in the sentence priming condition $(r(28)=.383, p<.05)$. However, for bilinguals, REVT scores $(r(28)=.523, p=.004)$ and PPVT scores were significantly correlated $(r(28)=-.546, p=.002)$ in the spontaneous condition. There was a moderate partial correlation between REVT scores and total number of accuracies $(r(28)=.520, p=.004)$ as were NWR scores and total number of accuracies $(r(28)=.412, p=.03)$ in the sentence priming condition (Tables 3 and 4 ).

\section{Predicting task performance}

Stepwise regressions were used to determine how much of the sentence production performance could be explained by vocabulary size, age, and working memory capacity. The results are shown

Table 3. Correlation and partial correlation matrices adjusting for age-related variance for monolinguals $(\mathrm{N}=30)$

\begin{tabular}{cllccc}
\hline & & REVT & NWR & $\begin{array}{c}\text { Spontane- } \\
\text { ous }\end{array}$ & Priming \\
\hline Correlation & NWR & $.650^{* *}$ & - & - & - \\
& Spontaneous & $.866^{* *}$ & $.545^{* *}$ & - & - \\
& Priming & $.787^{* *}$ & $.656^{* *}$ & $.865^{* *}$ & - \\
& Age & $.920^{* *}$ & $.579^{* *}$ & $.860^{* *}$ & $.842^{* *}$ \\
Partial & NWR & .367 & - & - & - \\
correlation & Spontaneous & $.371^{*}$ & .112 & - & - \\
& Priming & .061 & $.383^{*}$ & $.510^{* *}$ & - \\
\hline
\end{tabular}

REVT-R=Receptive and Expressive Vocabulary Test-receptive only (Kim, Hong, Kim, Jang, \& Lee, 2009); NWR= non-word repetition task (Lee, Kim, \& Yim, 2013). ${ }^{*} p<.05,{ }^{* *} p<.01$. in Table 5.

For monolinguals' performance under the spontaneous condition, $74.9 \%$ of the variance was accounted for in this regression. The only significant predictor under spontaneous condition was REVT scores. For monolinguals' performance under the sentence priming condition, the full regression model accounted for $75.1 \%$, in which age accounted for $70.9 \%$ of the variance and NWR scores accounted for an additional $4.2 \%$ of the variance.

A separate regression model accounted for $77.6 \%$ of the variance in the bilinguals' performance under spontaneous condition. REVT scores explained $77.6 \%$ of the variance, contributing the most. Age accounted for an additional 3.8\% and PPVT scores added 3.1\% of the variance. For bilinguals' performance under the sentence prim-

Table 5. Results of stepwise regression predicting sentence combining task

\begin{tabular}{clccc}
\hline & \multicolumn{1}{c}{ Step $^{\mathrm{a}}$} & $R^{2}$ & Cumulative $R^{2}$ & $p$-value \\
\hline M0 group & Spontaneous & - & - & - \\
& REVT & .749 & .749 & .000 \\
& Priming & - & - & - \\
& Age & .709 & .709 & .000 \\
& NWR & .042 & .751 & .040 \\
Bl group & Spontaneous & - & - & - \\
& REVT & .776 & .776 & .000 \\
& Age & .038 & .814 & .026 \\
& PPVT & .031 & .845 & .031 \\
& Priming & - & - & - \\
& REVT & .712 & .712 & .000 \\
& NWR & .041 & .753 & .044
\end{tabular}

$\mathrm{MO}=$ typically developing Korean speaking monolingual children; $\mathrm{Bl}=$ typically developing Korean-English bilingual children; REVT-R=Receptive and Expressive Vocabulary Test-receptive only (Kim, Hong, Kim, Jang, \& Lee, 2009); NWR=non-word repetition task (Lee, Kim, \& Yim, 2013).

${ }^{a} \mathrm{~N}=30$ in each regression, ${ }^{\mathrm{b}}$ Significance levels for the point at which the predictor variable was entered into the regression.

Table 4. Correlation and partial correlation matrices adjusting for age-related variance for the bilinguals $(\mathrm{N}=30)$

\begin{tabular}{|c|c|c|c|c|c|c|}
\hline & & REVT & PPVT & NWR & Spontaneous & Priming \\
\hline Correlation & $\begin{array}{l}\text { PPVT } \\
\text { NWR } \\
\text { Spontaneous } \\
\text { Priming } \\
\text { Age }\end{array}$ & $\begin{array}{l}-.162 \\
.616^{* *} \\
.881^{* *} \\
.844^{* *} \\
.870^{* *}\end{array}$ & $\begin{array}{c}- \\
-.005 \\
-.216 \\
-.102 \\
.069\end{array}$ & $\begin{array}{c}- \\
- \\
.616^{* *} \\
.679^{* *} \\
.606^{* *}\end{array}$ & $\begin{array}{c}- \\
- \\
- \\
.883^{* *} \\
.862^{* *}\end{array}$ & $\begin{array}{c}- \\
- \\
- \\
- \\
.789^{* *}\end{array}$ \\
\hline Partial correlation & $\begin{array}{l}\text { PPVT } \\
\text { NWR } \\
\text { Spontaneous } \\
\text { Priming }\end{array}$ & $\begin{array}{l}-.451^{*} \\
.226 \\
.523^{* *} \\
.520^{* *}\end{array}$ & $\begin{array}{l}- \\
-.059 \\
-.546^{* *} \\
-.255\end{array}$ & $\begin{array}{c}- \\
- \\
.232 \\
.412^{*}\end{array}$ & $\begin{array}{c}- \\
- \\
- \\
.651^{* *}\end{array}$ & $\begin{array}{l}- \\
- \\
-\end{array}$ \\
\hline
\end{tabular}

REVT-R=Receptive and Expressive Vocabulary Test-receptive only (Kim, Hong, Kim, Jang, \& Lee, 2009); PPVT=Peabody Picture Vocabulary Test fourth edition (Dunn \& Dunn, 2007); NWR=non-word repetition task (Lee, Kim, \& Yim, 2013).

${ }^{*} p<.05,{ }^{* *} p<.01$. 
ing condition, $75.3 \%$ of the variance was explained by REVT scores (71.2\%) and NWR scores (4.1\%).

\section{CONCLUSION}

The present study investigated complex sentence production of bilingual children compared to monolingual children in a sentence combining task under spontaneous and priming conditions. Three issues were addressed. The first was whether bilingual children would perform similarly to monolingual children under both conditions. The second was to reveal factors that significantly predict children's performance on sentence combining tasks. The last examined whether predictors for complex sentence production are similar or not between monolingual and bilingual children. Monolinguals performed better than bilinguals, and older children scored significantly higher than younger children. Children performed significantly better in compound sentences and also showed better performance under the sentence priming condition. The difference between the performance level of the two sentence types reduced as children got older. In addition, there was a greater sentence priming effect in embedded sentences. These findings are similar to previous studies (Bialystok, 2001; Lee, 2010; Thomas et al., 2014; Yip \& Matthews, 2007) in which children's performances increased with maturation and with the presence of prime sentences.

Monolinguals still outperformed bilinguals in complex sentence production even when they were under the priming condition. In both groups, receptive vocabulary knowledge was the most important variance in explaining complex sentence production under the spontaneous condition. However, under the priming condition, bilinguals differed from monolinguals, in that receptive vocabulary knowledge was still the most important variable in predicting complex sentence production, whereas age was the most important variable for monolinguals. Finally, as expected, working memory was critical factor when children were to produce sentences under the priming condition.

The study tested if children perform better in the structural priming condition, and if bilinguals would show performance as good as monolinguals. Both groups showed enhanced performance with the presence of priming sessions, indicating that structural priming taps the abstract linguistic ability. This has been reported before (Shin \& Christianson, 2009). The sentences children spontaneously produce represent merely ephemeral syntactic ability, and the importance of the language knowledge that lies underneath should not be overlooked. The results also are consistent with the findings that priming may have activated abstract language knowledge, since performance in the priming condition increased in both groups. However, different from our expectation, monolinguals still outperformed bilinguals. Bilinguals in this study had equivalent receptive vocabulary scores measured by REVT (Lee et al., 2013; Marchman et al., 2010) and linguistic working memory scores (measured by NWR) to monolinguals. Thus, it was anticipated that bilinguals would perform similarly to monolinguals under the priming condition. One possible explanation for the finding is that the receptive vocabulary test only taps vocabulary size, not necessarily higher level of language ability. Complex sentence development depends on more than vocabulary development; children need to learn syntactic rules and be able to position grammatical morphemes. Thus, bilinguals' vocabulary knowledge would not have represented the overall language development. Results support the hypothesis that bilinguals even with comparable vocabulary skills and linguistic working memory span to monolinguals can still lack higher language skills, such as complex sentence production (Luo et al., 2010; Windsor et al., 2010; Yip \& Matthews, 2007). However, one last note to these findings is that our complex sentence production was measured only in Korean. Bilingual children's language knowledge is distributed in two language systems (Kohnert, 2007) and that is the reason why their language knowledge, such as vocabulary, should be measured in both languages (Core, Hoff, Rumiche, \& Señor, 2013). Even though it is more challenging to directly compare and contrast two sentence skills in both languages due to the syntactic difference between languages, it may be necessary to measure sentence production skills in both languages in order to better describe bilinguals' overall language performance

With respect to the sentence types, the embedded sentences resulted in more enhancement than the compound sentences under the structural priming condition. This is likely because the embedded sentences mature later (McKee \& McDaniel, 2001). Particularly, the older group's performance in compound sentences al- 
most approached a ceiling, leaving small room for the performance to be elevated. This also is in line with the syntactic developmental hierarchy, showing that the compound sentences were easier to learn and produce. On the other hand, the performance of the embedded sentence types were markedly enhanced, leaving room for the existence of language knowledge children may not have shown spontaneously. This reflects the priming effect related to the previous language experience at the functional level (Bernolet \& Hartsuiker, 2010; Shin \& Christianson, 2009). Furthermore, it is expected that structural priming could be used as a facilitator in grammatical teaching (Leonard, 2011) as well as in second language learning (McDonough \& MacKey, 2008).

Correlational and stepwise regressions were used to determine how much of the performance could be explained by the vocabulary size, age, and working memory capacity. For both groups, the total number of accuracies in the spontaneous condition was significantly correlated with the priming condition. In the monolingual group, REVT scores significantly correlated to the spontaneous condition and NWR significantly correlated with the priming condition. Thus, vocabulary size is a basic linguistic skill for producing complex sentence and, as expected working memory is an important cognitive resource for priming. These correlational results were confirmed by stepwise regression analysis in which monolinguals' performances on the task under the spontaneous condition were predicted by REVT scores. Additionally, the performances under the sentence priming condition were predicted by age and NWR scores.

As confirmed in the monolingual group, age and REVT and PPVT scores significantly correlated with spontaneous condition in the bilingual group in which PPVT correlational coefficients were negative. The results may be explained by the fact that REVT and PPVT scores were negatively correlated $(r=-.451, p<.05)$. Bilingual children in this study were Korean-English bilingual children whose native language was Korean and school language was English. These children all live in Korea, in which the society language is Korean, Korean-English bilingual children living in Korea may have dominancy in Korean rather than English (Şimşek, 2006). Thus, even bilingual children in this study were good performers in both languages; there was a definite dominancy within individual level in which Korean was dominant and English was a non-dominant language. Experimental tasks were administered in Korean and, since linguistic knowledge is tightly linked to complex sentence production, Korean vocabulary skills measured by REVT might have had a stronger influence on sentence combining task performance. Regression analysis results confirmed that REVT scores were the most significant predictors in bilinguals. Thus, for future study, it is recommended to measure complex sentence production in both languages when examining bilingual children's performance.

While age and NWR scores were the variables that significantly predicted the complex sentence production in the priming condition in the monolingual group, NWR and REVT scores significantly explained the variance in the bilingual group. This makes intuitive sense; children develop their complex sentence production abilities along with the expansion of vocabulary size and working memory capacity growth as they mature (Thomason et al., 2009). On the other hand, bilinguals' performances under the priming condition were predicted by NWR scores along with REVT scores. The performance under priming condition in both groups were predicted by NWR scores, which means that working memory capacity was an important predictor for structural priming (Ellis Weismer \& Thordardottir, 2002; Joanisse \& Seidenberg, 1998; Montgomery \& Evans, 2009). This result echoes that of Ledoux et al. (2007) in terms of proving the interaction between working memory capacity and structural priming. Unlike the monolinguals, a significant proportion of the bilinguals' performance was predicted by REVT scores even under the priming condition. One possible explanation for these results is that bilingual children's age does not represent the same as in monolingual children. In monolingual group, age positively correlates with receptive vocabulary knowledge, while bilingual children's age and receptive vocabulary skills does not always positively correlate. Thus, in monolinguals age can explain much of the variance. However, bilingual children's age does not carry the same amount of importance as in monolinguals. Additionally, bilinguals' vocabulary knowledge is influenced by many factors, such as the timing and the amount of exposure to each language, and the social status of each language (Bialystok, 2001).

In this study, it was confirmed that age (younger vs. older), priming condition (spontaneous vs. priming), and complex sentence 
condition (compound vs. embedded) affected complex sentence production. More importantly, bilingual children showed different characteristics in explaining complex sentence production compared to monolinguals. Lastly, vocabulary size was an important factor in predicting spontaneous complex sentence production while working memory was a critical factor for complex sentence production in the priming condition. Structural priming was used to test future potential for use in accurate assessment of bilingual children's underlying sentence structure knowledge. Thus, for future studies it will be important to include a group of bilinguals with language delay and also complex sentence production in both languages should be examined to determine how bilinguals' performance changes, and how the two languages influence each other.

\section{REFERENCES}

Baker, C. (2006). Foundations of bilingual education and bilingualism (4th ed.). Tonawanda, NY: Multilingual Matters Ltd.

Bedore, L. M., Peña, E. D., García, M., \& Cortez, C. (2005). Conceptual versus monolingual scoring: when does it make a difference? Language, Speech, and Hearing Services in Schools, 36, 188-200.

Bernolet, S., \& Hartsuiker, R. J. (2010). Does verb bias modulate syntactic priming? Cognition, 114, 455-461.

Bialystok, E. (2001). Bilingualism in development: language, literacy, and cognition. New York, NY: Cambridge University Press.

Bialystok, E., Luk, G., Peets, K. F., \& Yang, S. (2010). Receptive vocabulary differences in monolingual and bilingual children. Bilingualism: Language and Cognition, 13, 525-531.

Bock, K. (1986). Syntactic persistence in language production. Cognitive Psychology, 18, 355-387.

Bock, K., \& Loebell, H. (1990). Framing sentences. Cognition, 35, 1-39.

Bock, K., Dell, G. S., Chang, F., \& Onishi, K. H. (2007). Persistent structural priming from language comprehension to language production. Cognition, 104, 437-458.

Branigan, H. P., Pickering, M. J., \& McLean, J. F. (2005). Priming prepositional-phrase attachment during comprehension. Journal of Experimental Psychology: Learning, Memory, and Cognition, 31, 468-481.

Campbell, T., Dollaghan, C., Needleman, H., \& Janosky, J. (1997). Reducing bias in language assessment: processing-dependent measures. Journal of Speech, Language, and Hearing Research, 40, 519-525.
Core, C., Hoff, E., Rumiche, R., \& Señor, M. (2013). Total and conceptual vocabulary in Spanish-English bilinguals from 22 to 30 months: implications for assessment. Journal of Speech, Language, and Hearing Research, 56, 16371649.

Danahy, K., Windsor, J., \& Kohnert, K. (2007). Counting span and the identification of primary language impairment. International Journal of Language \& Communication Disorders, 42, 349-365.

Dunn, L. M., \& Dunn, D. M. (2007). Peabody Picture Vocabulary Test Fourth Edition. San Antonio, TX: Pearson.

Ellis Weismer, S., \& Thordardottir, E. (2002). Cognition and language. In P. J. Accardo et al. (Eds.), Disorders of language development (pp. 21-37). Baltimore, MD: York Press.

Ellis, R. (2005). Principles of instructed language learning. System, 33, 209224.

Fernandez, M. C., Pearson, B. Z., Umbel, V. M., Oiler, D. K., \& Molinet-Molina, M. (1992). Bilingual receptive vocabulary in Hispanic preschool children. Hispanic Journal of Behavioral Sciences, 14, 268-276.

Ferreira, V. S., Bock, K., Wilson, M. P., \& Cohen, N. J. (2008). Memory for syntax despite amnesia. Psychological Science, 19, 940-946.

Fox Tree, J. E., \& Meijer, P. J. (1999). Building syntactic structure in speaking. Journal of Psycholinguistic Research, 28, 71-90.

Goldwater, M. B., Tomlinson, M. T., Echols, C. H., \& Love, B. C. (2011). Structural priming as structure-mapping: children use analogies from previous utterances to guide sentence production. Cognitive Science, 35, 156-170.

Harris, M. B., \& Hassemer, W. G. (1972). Some factors affecting the complexity of children's sentences: the effects of modeling, age, sex, and bilingualism. Journal of Experimental Child Psychology, 13, 447-455.

Hatzidaki, A., Branigan, H. P., \& Pickering, M. J. (2011). Co-activation of syntax in bilingual language production. Cognitive Psychology, 62, 123-150.

Hemsley, G., Holm, A., \& Dodd, B. (2006). Diverse but not different: the lexical skills of two primary age bilingual groups in comparison to monolingual peers. International Journal of Bilingualism, 10, 453-476.

Hoff, E., Core, C., Place, S., Rumiche, R., Señor, M., \& Parra, M. (2012). Dual language exposure and early bilingual development. Journal of Child Language, 39, 1-27.

Joanisse, M. F., \& Seidenberg, M. S. (1998). Specific language impairment: a deficit in grammar or processing? Trends in Cognitive Sciences, 2, 240-247.

Kim, Y. T., Hong, G. H., Kim, K. H., Jang, H. S., \& Lee, J. Y. (2009). Receptive \& expressive vocabulary test (REVT). Seoul: Seoul Community Rehabilitation Center. 
Kohnert, K. (2007). Language disorders in bilingual children and adults. San Diego, CA: Plural Publishing.

Kohnert, K., Windsor, J., \& Ebert, K. D. (2009). Primary or "specific" language impairment and children learning a second language. Brain and Language, 109, 101-111.

Kohnert, K., Windsor, J., \& Yim, D. (2006). Do language-based processing tasks separate children with language impairment from typical bilinguals? Learning Disabilities Research \& Practice, 21, 19-29.

Ledoux, K., Traxler, M. J., \& Swaab, T. Y. (2007). Syntactic priming in comprehension: evidence from event-related potentials. Psychological Science, $18,135-143$.

Lee, H. J., Kim, Y. T., \& Yim, D. (2013). Non-word repetition performance in Korean-English bilingual children. International Journal of Speech-Language Pathology, 15, 375-382.

Lee, Y. K. (2010). The development of complex sentence production of schoolaged children. Journal of Speech \& Hearing Disorders, 19, 159-178.

Leonard, L. B. (2011). The primacy of priming in grammatical learning and intervention: a tutorial. Journal of Speech, Language, and Hearing Research, $54,608-621$.

Leseman, P. P. (2000). Bilingual vocabulary development of Turkish preschoolers in the Netherlands. Journal of Multilingual and Multicultural Development, 21, 93-112.

Levey, S., \& Polirstok, S. (2010). Language development: understanding language diversity in the classroom. Thousand Oaks, CA: SAGE Publications.

Luka, B. J., \& Barsalou, L. W. (2005). Structural facilitation: mere exposure effects for grammatical acceptability as evidence for syntactic priming in comprehension. Journal of Memory and Language, 52, 436-459.

Luo, L., Luk, G., \& Bialystok, E. (2010). Effect of language proficiency and executive control on verbal fluency performance in bilinguals. Cognition, 114, 29-41.

Malhotra, G. (2009). Dynamics of structural priming (Doctoral dissertation). University of Edinburgh, UK.

Marchman, V. A., Fernald, A., \& Hurtado, N. (2010). How vocabulary size in two languages relates to efficiency in spoken word recognition by young Spanish-English bilinguals. Journal of Child Language, 37, 817-840.

McDonough, K., \& Mackey, A. (2008). Syntactic priming and ESL question development. Studies in Second Language Acquisition, 30, 31-47.

McKee, C., \& McDaniel, D. (2001). Resumptive pronouns in English relative clauses. Language Acquisition, 9, 113-156.

Montgomery, J. W., \& Evans, J. L. (2009). Complex sentence comprehension and working memory in children with specific language impairment. Journal of Speech, Language, and Hearing Research, 52, 269-288.

Moon, S. B., \& Byun, C. J. (2003). Korean-Kaufman Assessment Battery for Children (K-ABC). Seoul: Hakjisa.

Pearson, B. Z. (1998). Assessing lexical development in bilingual babies and toddlers. International Journal of Bilingualism, 2, 347-372.

Peña, E., Bedore, L., \& Zlatic-Giunta, R. (2002). Use of a category generation task to assess vocabulary skills of Spanish-English bilinguals. Journal of Speech, Language, and Hearing Research, 46, 938-947.

Reitter, D., Keller, F., \& Moore, J. D. (2011). A computational cognitive model of syntactic priming. Cognitive Science, 35, 587-637.

Savage, C., Lieven, E., Theakston, A., \& Tomasello, M. (2006). Structural priming as implicit learning in language acquisition: the persistence of lexical and structural priming in 4-year-olds. Language Learning and Development, 2, 27-49.

Scheepers, C., Sturt, P., Martin, C. J., Myachykov, A., Teevan, K., \& Viskupova, I. (2011). Structural priming across cognitive domains from simple arithmetic to relative-clause attachment. Psychological Science, 22, 1319-1326.

Shin, J. A., \& Christianson, K. (2009). Syntactic processing in Korean-English bilingual production: evidence from cross-linguistic structural priming. Cognition, 112, 175-180.

Şimşek, S. Ç. S. (2006). Third language acquisition: Turkish-German bilingual students' acquisition of English word order in a German educational setting. Münster: Waxmann Verlag.

Teoh, W. Q., Brebner, C., \& McCormack, P. (2012). Assessing the language skills of children from culturally and linguistically diverse backgrounds: the expressive vocabulary performance of Singaporean English-Mandarin bilingual pre-schoolers. International Journal of Speech-Language Pathology, 14, 281-291.

Thomas, E. M., Williams, N., Jones, L. A., Davies, S., \& Binks, H. (2014). Acquiring complex structures under minority language conditions: bilingual acquisition of plural morphology in Welsh. Bilingualism: Language and Cognition, 17, 478-494.

Thomason, M. E., Race, E., Burrows, B., Whitfield-Gabrieli, S., Glover, G. H., \& Gabrieli, J. D. (2009). Development of spatial and verbal working memory capacity in the human brain. Journal of Cognitive Neuroscience, 21, 316332.

Thothathiri, M., \& Snedeker, J. (2008). Syntactic priming during language comprehension in three-and four-year-old children. Journal of Memory and Language, 58, 188-213. 
Tsiamtsiouris, J., \& Cairns, H. S. (2009). Effects of syntactic complexity and sentence-structure priming on speech initiation time in adults who stutter. Journal of Speech, Language, and Hearing Research, 52, 1623-1639.

Weber, K., \& Indefrey, P. (2009). Syntactic priming in German-English bilinguals during sentence comprehension. NeuroImage, 46, 1164-1172.

Windsor, J., Kohnert, K., Lobitz, K. F., \& Pham, G. T. (2010). Cross-language nonword repetition by bilingual and monolingual children. American Journal of Speech-Language Pathology, 19, 298-310.

Yim, D., \& Rudoy, J. (2013). Implicit statistical learning and language skills in bilingual children. Journal of Speech, Language, and Hearing Research, 56, 310-322.

Yim, D., \& Windsor, J. (2010). The roles of nonlinguistic statistical learning and memory in language skill. Korean Journal of Communication Disor- ders, 15, 381-396.

Yim, D., Jo, Y., Han, J., \& Seong, J. (2016). Executive function in Korean-English bilingual children with and without vocabulary delay. Communication Sciences \& Disorders, 21, 472-487.

Yim, D., Kim, Y. T., \& Yang, Y. (2016). Exploring the utility of verbal and visuospatial working memory for identifying children with language impairment. Communication Sciences \& Disorders, 21, 193-205.

Yim, D., Yoon, S., \& Lee, J. (2016). Receptive vocabulary assessment in Korean-English bilingual children: cross-linguistic investigations. Communication Sciences \& Disorders, 21, 131-138.

Yip, V., \& Matthews, S. (2007). Relative clauses in Cantonese-English bilingual children: typological challenges and processing motivations. Studies in Second Language Acquisition, 29, 277-300. 


\section{국문초록}

\section{구문 점화 효과를 통해 살펴본 한국어-영어 이중언어 아동의 복문 산출 능력}

\section{김보경 · 임동선}

이화여자대학교 언어병리학과

배경 및 목적: 복문은 아동 구문 발달에 중요한 측정지표이나, 이중언어 아동의 언어 능력은 그 다양성으로 인해 정확한 측정이 어렵 다. 이 연구는 구문점화 효과를 통해 살펴본 이중언어 아동의 복문 산출 능력을 살펴보고자 했다. 방법: 6-12세 이중언어 사용 아동 30 명과 단일언어 사용 아동 30 명이 연구에 참여하였으며, 모든 아동은 정상 인지능력을 지녔고, 언어능력도 정상적으로 발달하는 아동 들이었다. 이들은 자발상황과 구문점화 상황에서 내포문과 접속문을 연결하는 과제를 수행하였다. 결과: 단일언어 아동이 이중언어 아동보다, 연령이 높은 아동이 낮은 아동보다 높은 수행을 보였다. 모든 아동은 접속문과 구문점화 상황에서 더 높은 수행을 보였다. 두 집단에서 어휘능력이 자발상황을 예측하는데 중요한 요소로 나타났다. 또한 구문점화 상황에서는 단일언어 아동은 생활연령과 비단 어 따라말하기 능력이 수행을 예측하는데 중요한 요소였지만 이중언어 아동은 비단어 따라말하기와 어휘능력이 수행을 예측하는데 중요한 요소였다. 논의 및 결론: 구문점화 효과를 통한 복문 산출 능력은 어휘력과 작업 기억력이 중요한 요소로 작용하고 있음이 나타 났고, 그 양상은 이중언어 아동과 단일언어 아동이 다르게 나타났다.

핵심어: 이중언어 아동, 복문 산출, 구문 점화

본 연구는 2016년도 이화여자대학교 교내 연구비 지원에 의해 수행되었음. 